\title{
Resistance of benthic intertidal communities to multiple disturbances and stresses
}

\author{
Laetitia Joseph, Mathieu Cusson* \\ Département des sciences fondamentales, Université du Québec à Chicoutimi, 555 boulevard de l'Université, Chicoutimi, \\ Québec G7H 2B1, Canada
}

\begin{abstract}
Many ecosystems are facing biodiversity loss and environmental change due to anthropogenic activities, with these impacts occurring within the context of natural disturbance. Understanding ecosystem functioning and the response of communities to these impacts is necessary in order to evaluate the effects of future environmental change. The aim of this study was to determine the consequences of the loss of key species on the structure and function of intertidal communities in a context of nutrient enrichment, so as to ascertain the resistance of these communities when disturbance and stresses are compounded. Subarctic rocky intertidal communities in Quebec were subjected to an orthogonal factorial field experiment with 3 stress factors (macroalgae canopy loss, grazer exclusion, and nutrient enrichment), each with 2 disturbance levels. Simple and interactive effects of these factors were followed for $4 \mathrm{mo}$, and responses in structure (\% cover and biomass) and productivity were evaluated. The communities that were not subjected to canopy loss showed greater resistance and very limited effects from enrichment and grazer reduction. The loss of canopy altered the community structure (e.g. reduction in richness and biomass) and functioning (reduced productivity), probably due to increased temperatures and desiccation. This lack of resistance was amplified through the addition of a stress. The application of multiple stresses within field experiments allows for a better understanding of the mechanisms affecting community structure and ecosystem functioning under situations of increased natural and anthropogenic stress.
\end{abstract}

KEY WORDS: Community structure - Functional response - Multiple stressors · Resistance • Canopy disturbance $\cdot$ Grazers $\cdot$ Nutrient addition · Rocky intertidal

Resale or republication not permitted without written consent of the publisher

\section{INTRODUCTION}

In many ecosystems, natural disturbances are coupled with human activities, affecting both abiotic and biotic properties of the system (Vitousek et al. 1997b, Tilman \& Lehman 2001). Habitat destruction (Tole 2002, Hanski 2005), pollution (McNeely 1992) and alterations of biogeochemical cycles (e.g. carbon and nitrogen) by human activities (Vitousek et al. $1997 a, b)$ negatively impact the structure and functioning of many ecosystems (Vitousek et al. 1997b, Hooper et al. 2005). Biodiversity loss is a major threat to ecosystem functioning (Tilman 1999, Hooper et al.
2005) and may be considered equal in importance to other major environmental changes (e.g. climate warming, nutrient loading) in terms of the effects on overall ecosystem health (Hooper et al. 2012). Biodiversity can play an important role in countering stresses on ecosystems; therefore, understanding the consequences of biodiversity loss for ecosystems has prompted numerous ecological studies (Grime 1997, Loreau et al. 2002, Worm et al. 2006).

The link between biodiversity and ecosystem stability has been well studied (MacArthur 1955, Elton 1958, Pimm 1984, Tilman 1996, Lehman \& Tilman 2000). Greater diversity generally increases the sta- 
bility of ecosystems as a greater number of species will encompass a broader range of functional traits and response strategies to disturbance (Tilman 1996, Yachi \& Loreau 1999). An essential attribute of ecosystem stability is therefore resistance (or 'inertia' sensu Underwood 1989), which is defined as the capacity of a system to remain unchanged when faced with disturbance or stress (Grimm \& Wissel 1997).

The presence of certain key species may increase the stability (and resistance) of a community (Maggi et al. 2009, Watson \& Estes 2011). In the context of biodiversity loss, the disappearance of key species will likely have a major effect on ecosystem functioning. For instance, habitat-forming species (or ecosystem engineers and bioengineers, sensu Jones et al. 1994) offer refuge and protection for numerous organisms and thus play a crucial role in ecosystem functioning. The loss of habitat-forming species has a negative impact on the surrounding community through a reduction in associated species richness and abundance (Rueda et al. 2009, Watt \& Scrosati 2013).

Habitat-forming macroalgae, often dominating the intertidal zone of rocky shore habitats, are considered key species for their ecosystem (Hawkins \& Hartnoll 1983). They play an important role in structuring the community (Hawkins \& Harkin 1985), providing a food supply (Hawkins \& Hartnoll 1983), modifying physical conditions and reducing physical stress (e.g. desiccation and wave action) for the understorey community (Bertness \& Leonard 1997, Bertness et al. 1999). However, sweeping by canopy algae may also have negative effects on the understorey (Jenkins et al. 1999b). Currently, macroalgae (including fucoids) are undergoing a global decline (Walker \& Kendrick 1998, Airoldi \& Beck 2007) caused by both climate change and other regional and local-scale human impacts (Hawkins et al. 2009). This loss of fucoids will therefore have major consequences for the understorey community (Jenkins et al. 1999a, Worm \& Duffy 2003) by reducing species richness (Schiel \& Lilley 2011, Watt \& Scrosati 2013) and enhancing ephemeral algae recruitment (Jenkins et al. 1999a, Bulleri et al. 2002, Schiel \& Lilley 2007). Moreover, changes in the abundance of macroalgae could also affect community function by reducing primary production (Tait \& Schiel 2011, Crowe et al. 2013).

Grazers are also an important element structuring intertidal communities, especially during early succession, applying strong top-down control on algal recruitment (Hawkins \& Hartnoll 1983, Anderson \& Underwood 1997, Jenkins et al. 2005), thereby influ- encing the course of species succession. Grazer exclusion often leads to inhibition of later successional taxa (e.g. Fucus spp.) by ungrazed, early settling ephemeral algae such as Ulva spp. or Porphyra spp. (see Lubchenco 1983, Anderson \& Underwood 1997). On the other hand, human activities that generate nutrient enrichment in coastal environments (e.g. Paerl 1997, Allen et al. 1998) may lead to increases in the abundance of ephemeral algae (Korpinen et al. 2007, Kraufvelin et al. 2010), that exacerbate bottom-up controls within communities. Biodiversity can be an important factor buffering against this nutrient loading. For example, canopy and grazer loss lead to a community more sensitive to nutrient addition, and an increased abundance of ephemeral algae (e.g. Worm \& Lotze 2006), while the effects on invertebrates are unknown. Such removals simulate anthropogenic removal of canopies (e.g. fucoid harvesting, Ugarte \& Sharp 2001) or the collection of grazers (Martins et al. 2010).

Ecological communities are often exposed to multiple interacting disturbances and stresses, both natural and anthropogenic. Studying the potential effects (synergic or antagonistic) of these disturbances and stresses on communities will contribute to our understanding of the cumulative impacts that shape communities. Single, isolated effects of canopy or grazer removal and enrichment have been broadly studied, yet few studies have simultaneously examined the coupled impacts of biodiversity loss and stress. Eriksson et al. (2007) made field manipulations using multiple treatments, but their study focused only on algal community responses (e.g. understorey and recruits). Multiple interactive impacts on both macroalgae and macroinvertebrate assemblage structure and function have not yet been properly studied.

The aim of our study was to determine the in situ consequences of the loss of key species (macroalgae canopy and grazers) on ecosystem structure and functioning in the presence of nutrient enrichment and to evaluate the resistance of the benthic community when species loss and stress are coupled. Specifically, we evaluated the response of subarctic benthic communities subjected to both single and interactive effects of canopy removal, grazer exclusion and nutrient enrichment on community structure and functioning (by using community productivity and respiration) and the resistance of intertidal rocky shore communities. This study also provides insight into the respective role of top-down controls, ecosystem engineers and bottom-up forcing in shaping community structure and ecosystem functioning (see also Thompson et al. 2004, Crowe et al. 2011). Such 
forcing is not yet understood for the subarctic ecosystem of the St. Lawrence Estuary. This site was selected as it is subjected to both natural and anthropogenic stressors including ice-scouring (Archambault \& Bourget 1983, Bergeron \& Bourget 1984), a predicted increase in water movements (Savard et al. 2008), along with eutrophication (Thibodeau et al. 2006, Gilbert et al. 2007) all which may affect the abundance of macroalgae and grazers in benthic intertidal communities. We hypothesized that in addition to a significant impact from canopy and grazer removal individually, community structure and ecosystem functioning would be even more affected due to synergetic effects when these disturbances are coupled with nutrient enrichment stress.

\section{MATERIALS AND METHODS}

\section{Study site}

The experiment was conducted between May and September 2012 near the village of Sainte-Flavie on the south shore of the St. Lawrence Estuary, Quebec, Canada $\left(48^{\circ} 37^{\prime} 42.5^{\prime \prime} \mathrm{N}, 68^{\circ} 11^{\prime} 55.7^{\prime \prime} \mathrm{W}\right)$. The study area is representative of a subarctic flat rocky shore habitat as it is subjected to ice-scouring during winter and early spring (Archambault \& Bourget 1983, Bergeron \& Bourget 1984). Temperature and salinity range from 4 to $16^{\circ} \mathrm{C}$ and 24 to $29 \%$, respectively (Fradette \& Bourget 1980, Archambault \& Bourget 1983). The intertidal fauna and flora are characteristic of a moderately wave-disturbed environment (Archambault \& Bourget 1983). In the mid-intertidal zone, the macroalgal canopy is composed of Fucus spp. (F. distichus edentatus and F. vesiculosus) and the invertebrate assemblage is dominated by gastropod grazers (Littorina obtusata and L. saxatilis; see Table S1 in the Supplement at www.int-res.com/articles/suppl/534 p049_supp.pdf for a complete list) and by filter feeder blue mussels (composed of Mytilus edulis, M. trossulus and hybrids, hereafter referred to as Mytilus spp.). The shores of the estuary are often covered with ice during the winter (midDecember until the end of March); the ice sheet provides protection for the biological assemblages against extreme cold. The ice, however, may also act as an indiscriminate disturbance factor on the flat rock surfaces and exposed crevices through heavy ice-scouring (Bergeron \& Bourget 1984, Åberg 1992, McKindsey \& Bourget 2001).

\section{Experimental design}

We used an orthogonal factorial experimental design in order to evaluate the effects of biodiversity loss (canopy [Ca], 2 levels; grazer [Gr], 2 levels) and nutrient enrichment (Nu, 2 levels) on the structure and functioning of the intertidal benthic communities (Fig. 1). All 8 treatments from this design, and a procedural control (for the grazer exclusion; see below) were replicated 4 times $(n=4)$ and randomly assigned to 36 experimental plots $(50 \times 50 \mathrm{~cm})$ on emergent rocky substrates within our study area. All plots were placed at a similar height in the mid-intertidal zone (average of $1.34 \pm 0.20 \mathrm{~m}$ ), in a $400 \mathrm{~m}$ wide area. The experimental plots, marked using anchor screws, were haphazardly selected which fulfilled all the following criteria: homogenous flat substrate, lacking pools or large crevices, a minimum of $80 \%$ cover of Fucus spp. A minimum distance of $3 \mathrm{~m}$ between plots was respected so as to avoid treatment interaction.

For the canopy treatment, we had 2 treatment levels: canopy present $(\mathrm{C}+)$ where the canopy was untouched, and canopy absent $(\mathrm{C}-$ ) where all canopy taxa (i.e. Fucus spp.) holdfasts were removed within the $50 \times 50 \mathrm{~cm}$ area.

The grazer treatment also had 2 treatment levels: grazers present $(\mathrm{G}+)$ and grazers absent $(\mathrm{G}-)$. In the latter, the grazers L. obtusata, L. saxatilis and L. littorea, Tectura testudinalis, Margarites spp. and Jaera marina were removed by handpicking. The exclusion treatment was designed using a physical barrier composed of a thin layer of natural sticky

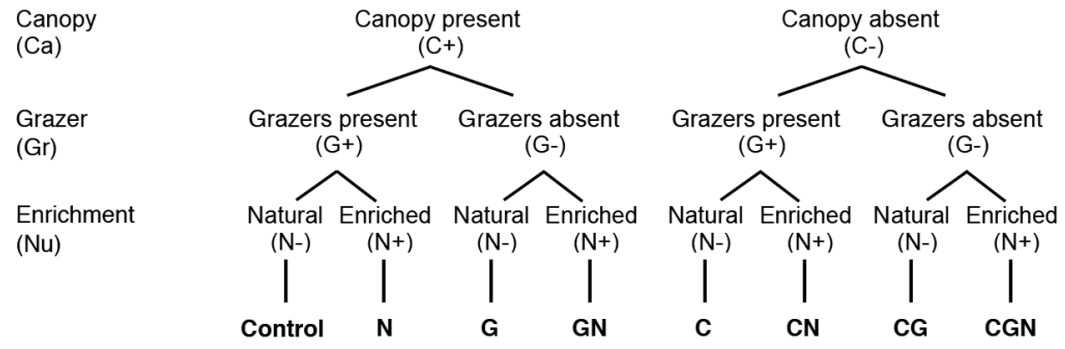

Fig. 1. Experimental design with the 3 stress factors (canopy, grazer and nutrient enrichment) having 2 levels each (see 'Materials and methods' for details). A total of 4 replicates for each treatment were used. Bottom row shows the letter codes used in the text and figures; 1 letter $=1$ stress (or treatment) applied, 2 letters $=2$ stresses, 3 letters $=3$ stresses (i.e. CGN: all 3 applied stresses) 
barrier (Tree Tanglefoot Insect Barrier; Contech) and a small twisted wire brush (2 $\mathrm{cm}$ diameter) placed on cleared $(\sim 5 \mathrm{~cm}$ width) surfaces along the contour of the experimental plot. When needed, these surfaces were smoothed using a small quantity of concrete (Poly-Plug Bomix; Daubois) and epoxy (West Systems). Procedural controls $(\mathrm{n}=4)$ with incomplete exclusions were also implemented in natural communities. No difference was observed between the control plots $(\mathrm{C}+, \mathrm{G}+$ and no enrichment) and the procedural controls for any response variables, with the exception of richness at the end of the experiment. At the study site, the abundance of small grazers $(<2 \mathrm{~mm})$ is great and the use of cages with small screens would certainly have had an effect on the natural communities. Moreover, the cageless grazers treatment used in this study did not have the undesired effects of light and flow reduction and detritus retention commonly observed with cage use (Range et al. 2008).

For the nutrient enrichment, 2 levels were used: natural conditions ( $\mathrm{N}-$ ) and enriched conditions $(\mathrm{N}+)$ where a controlled addition of slow-release fertilizer pellets of $14 \%$ nitrogen $\left(\mathrm{NO}_{3}-\mathrm{N}\right.$ and $\left.\mathrm{NH}_{3}-\mathrm{N}\right), 14 \% \mathrm{P}$ $\left(\mathrm{P}_{2} \mathrm{O}_{5}\right)$ and $14 \% \mathrm{~K}\left(\mathrm{~K}_{2} \mathrm{O}\right)$ (Smartcote ${ }^{\circ}$; Plant Prod) was used within the experimental plots. Enrichment through slow-release fertilizer pellets has been tested (Worm et al. 2000) and used in many habitats (Worm et al. 2000, Eriksson et al. 2006a, 2007, Korpinen et al. 2007, Jochum et al. 2012). This method produces independent nutrient treatments within a $2 \mathrm{~m}$ distance from the source (Worm et al. 2000). Two mesh bags containing $100 \mathrm{~g}$ of fertilizer pellets were screwed at the opposite corners of the $50 \times 50 \mathrm{~cm}$ plots and replaced every month. For all other experimental plots, inert control bags with washed pebbles were used to take into account any bag effects (e.g. as additional substrate). When replaced, the collected nutrient bags were weighed (dry weight loss) to estimate the amount of nutrient diffused into plots. An average of $31 \pm 0.15 \%$ of weight loss was observed, with a total estimated diffusion of $8.64 \pm$ $0.57 \mathrm{~g}$ of total nitrogen per month into each plot. This level of nutrient enrichment is comparable to moderate eutrophication, which is anticipated for the St. Lawrence Estuary (Gilbert et al. 2007). Pilot tests in the field showed a 3- to 6-fold increase in total nitrogen concentrations in water samples from an enriched quadrat compared to the natural concentration of the St. Lawrence Estuary. F. distichus edentatus tissues from control and nutrient-enriched plots were collected at the end of the experiment and their total nitrogen content was compared (analyzed at the
INRS Laboratory, Quebec City). The total nitrogen content values in the Fucus tissues from nutrientenriched plots were slightly higher than those in the controls (average of $1.06 \pm 0.05 \%$ and $0.95 \pm 0.04 \%$ nitrogen, respectively; $F_{1,20}=7.07, \mathrm{p}=0.015$ ), providing evidence that the additional nutrients had been incorporated into the algae.

Canopy and grazer treatments were 'press' type perturbation experiments (sensu Bender et al. 1984), as the experimental conditions of the species densities in the plots were altered and controlled every 9 to $11 \mathrm{~d}$ (maintenance sessions). During each inventory (see following sub-section) and during maintenance (between inventory periods), new Fucus spp. juveniles and grazers were estimated/counted and thereafter removed from the plots. Even when grazer abundance was reduced for several days (up to $4 \mathrm{~d}$; $\mathrm{L}$. Joseph, M. Cusson and S. Cimon unpubl. data), the grazer treatment $(\mathrm{G}-)$ failed to significantly reduce their abundance during the period between 2 maintenance sessions. However, although grazer removal efficiency failed (about $40 \%$ of the time) on a bimonthly time-scale, some statistically significant differences were observed for the grazer treatments and the treatment was not removed from data analyses. Thus the treatment is referred to as 'grazers reduced' rather than 'grazers absent', and was interpreted accordingly.

\section{Sampling}

Structure of the community

The community in each plot was sampled using a $30 \times 30 \mathrm{~cm}$ quadrat placed in the centre of the experimental plots. Non-destructive visual estimates of abundance as \% cover of all identified taxa $>1 \mathrm{~mm}$ (usually to species level) for each plot were made at 4 distinct times: Period 1 (June 2-9, before establishment of the treatments), Period 2 (July 1-8, 1 mo after the start of the treatments), Period 3 (July 31-August 6, 2 mo after the start of the treatments) and Period 4 (August 29-September 4, at the end of the experiment). Inventories were performed before any maintenance of the plot. The \% cover of macroalgae and mussels were estimated with the division of the $30 \times$ $30 \mathrm{~cm}$ frame into 25 equal squares, each representing $4 \%$ of the total quadrat cover. This latter procedure is common (e.g. Scrosati et al. 2011, Crowe et al. 2013), and use of the same unit among abundances is necessary in order to assess the community dominance profiles in our treatments. Mobile invertebrates were 
counted and later transformed into \% cover (e.g. regression to convert density in \% cover with $\mathrm{n}=129$, $\mathrm{R}^{2}=0.66$ for Littorina sp.; arbitrary value of $0.25 \%$ for each individual of $L$. littorea, $T$. testudinalis, and Nereis sp.; $0.1 \%$ for each individual of Lacuna vincta and Margarites sp.; $0.01 \%$ for each J. marina). The cover was estimated per species, so the total summed $\%$ in a plot often exceeded $100 \%$. Following the last visual inventory, we destructively sampled in order to collect all biomass (except crustose species) in the sampled $30 \times 30 \mathrm{~cm}$ plot. The biomass samples were sieved $(\varnothing 1 \mathrm{~mm})$ and all individuals were identified under a microscope and weighed $( \pm 0.00005 \mathrm{~g})$. Biomass was converted into energy $(\mathrm{kJ})$ by applying conversion factors from Brey et al. (2010).

\section{Functioning of the community}

To assess the effects of nutrient enrichment on community functioning with or without canopy, measures of primary production were estimated at the end of July, near midday over 3 consecutive sunny days. Estimates were derived from variations in $\mathrm{CO}_{2}$ concentration (ppm) using benthic chambers following the method described by Migné et al. (2002). Subsampled plots in each treatment $(\mathrm{n}=3$ for control and $\mathrm{N} ; \mathrm{n}=2$ for $\mathrm{C}$ and $\mathrm{CN}$ ) were randomly chosen for primary production measurements and randomly ordered during the sampling days. The chamber consisted of a transparent dome and a base of Plexiglas ${ }^{\odot}$ placed over the $30 \times 30 \mathrm{~cm}$ sampled community plot, then sealed airtight to the ground using neutral silicon. $\mathrm{CO}_{2}$ variations in the chamber were measured using an infrared $\mathrm{CO}_{2}$ gas analyzer (Li-800; LI-COR) and recorded on a data logger (Li-400; LI-COR) every $15 \mathrm{~s}$ for 15 to $20 \mathrm{~min}$. Measurements of $\mathrm{CO}_{2}$ concentrations were conducted at ambient light (>1000 $\mu$ mol photon $\mathrm{m}^{-2}$ measured at PAR, 600 to $700 \mathrm{~nm}$ ) for net primary production (NPP) and with an opaque polyethylene sheet placed over the chamber in order to measure respiration $(R)$. The $\mathrm{CO}_{2}$ fluxes for NPP and $R$ were calculated using the following formula:

Flux $\left(\mathrm{mmol} \mathrm{C} \mathrm{m}{ }^{-2} \mathrm{~h}^{-1}\right)=b(18.2 \times 60) /(22.4 \times 1000 \times$ 0.09)

where the slope, $b$, is obtained through a linear regression of the $\mathrm{CO}_{2}$ variations recorded from the chambers, $18.2=$ volume $(\mathrm{l})$ of air in the chamber, $60=$ min in an hour, $22.4=$ molar air by litre in molar volume. The gross primary production (GPP) of the community was then calculated by adding NPP and $R$. Note that this method is not used for calculating a global $\mathrm{CO}_{2}$ budget but serves to estimate the metabolic state of the community under the same conditions and for comparison among treatments.

\section{Data analysis}

All analyses were performed on the associated community only (unless otherwise stated); the manipulated taxa (Fucus spp. and grazer species) were excluded from the data prior to analyses.

To test for the effects of the treatments and the interactions between and among them, repeated measures of analysis of variance (RM-ANOVA) with 4 fixed factors (period: 3 levels; Ca, Gr and Nu: 2 levels each, see Table S2 in the Supplement) were performed on total abundance (sum of all species in \% cover within the $30 \times 30 \mathrm{~cm}$ sampled plots), richness $(S)$ and the Simpson's index of diversity $(1-\lambda)$. Period 1 was not included in the latter analysis. Following this test, we also applied separate 3-way ANOVAs (with factors of $\mathrm{Ca}, \mathrm{Gr}$ and $\mathrm{Nu}$ ) performed at each period in order to appreciate the evolution of any effects over time (see Table 1). A 3-way ANOVA was performed for total biomass abundance, as this variable was only available for the last period. Separate analyses of total abundance and richness of understorey algae and invertebrates (without grazers) were also performed. ANOVA assumptions were checked by graphical examination of the residuals (Montgomery 1991, Quinn \& Keough 2002); no transformations were necessary. When a factor was significant, a multiple comparison test (Tukey's HSD or if stated, Student's $t$ ) was performed to look at the differences between treatment levels. Comparisons of taxa abundance for some species were investigated using a $t$-test or Wilcoxon rank sum test when the assumptions of normality and equality of variances were not met.

The effects of the treatments on the structure of the community (in \% cover and biomass data, based on Bray-Curtis similarities) were investigated for each period using a permutational multivariate analysis of variance (PERMANOVA; Anderson et al. 2008) with 999 permutations and with the same factors $(\mathrm{Ca}, \mathrm{Gr}$, $\mathrm{Nu}$ ) as described above. Abundance data for \% cover and biomass were square-root transformed and fourth-root transformed, respectively, while data were transformed into presence-absence for effects on compositional community structure. The effects of the treatments were visualized using principal coordinate analysis (PCO). A similarity percentage analysis (SIMPER) was used to assess the percentage con- 
tribution of each taxon to the observed dissimilarities among treatments.

The effect of enrichment and canopy loss on GPP, NPP and $R$ were analyzed using a Kruskal-Wallis test (treatment fixed 4 levels) among control and $\mathrm{N}(\mathrm{n}=3)$ and $\mathrm{C}$ and $\mathrm{CN}(\mathrm{n}=2)$ treatments (see Fig. 1 for treatment details).

Univariate analyses were made using JMP v.10.0; multivariate analyses and ordinations were conducted using PRIMER+PERMANOVA v.6.1.6 (Clark \& Gorley 2006, Anderson et al. 2008). A significance level of $\alpha=0.05$ was used for all statistical tests, however, observed p-levels close to significance were carefully considered.

\section{RESULTS}

A total of 35 different taxa were observed at our site with an average $( \pm \mathrm{SE})$ of $9.0 \pm 0.3$ species $(\mathrm{min} .=$ 5 , max. = 19) per sampled quadrat $(30 \times 30 \mathrm{~cm})$. Eleven algal taxa were reported, the most abundant being Fucus distichus edentatus and Ralfsia clavata, along with 24 taxa of invertebrates with grazers (e.g. Littorina saxatilis, L. obtusata, Tectura testudinalis) and filter feeders (e.g. Mytilus spp.) being the most common. A list of all observed taxa is presented in Table S1 in the Supplement.

\section{Effects of single and multiple stresses}

\section{Community abundances and diversity indices}

The canopy, grazer and nutrient enrichment treatments had different effects on the associated community, and some of them varied among sampling periods. Total abundance in terms of \% cover was not affected by any of the treatments nor by period (Table 1, Table S2a in the Supplement), whereas in all treatments, the average values of richness and diversity were affected by period (Tables 1 \& S2b,c). Average richness values were significantly higher (more than 2-fold) at the end of the experiment (Period 4$)$ compared to the other periods $\left(F_{3,96}=147\right.$, $\mathrm{p}<0.0001)$. This was due to the addition of cryptic taxa (originating, for example, from sediments or in between the mussel aggregations) that had been collected during the destructive sampling method after the last inventory.

Some significant effects were detected before the start of the experiments (Period 1; Table 1). This cannot be easily explained as the treatments had not been yet implemented. Variation between the 2 categories of plots was, however, small in comparison to the differences observed later over the course of the experiment. Plots where the canopy cover was to remain had $3.75 \pm 0.32$ species and a Simpson's index of diversity of $0.51 \pm 0.03$, while plots where the canopy was to be removed had a lower richness $(2.88$ \pm 0.10 species) and a diversity of $0.39 \pm 0.03$. Treatments were randomly assigned to plots along a $400 \mathrm{~m}$ wide transect along the shore where some variability among natural communities can occur. However, no effects on community abundance structure were observed (see next section) and the significant effects observed in Period 1 had dissipated by Period 2 (see Table 1).

Species richness was significantly affected by the Period $\times$ Ca interaction (Table 1) and differences were seen in both Periods 3 and 4 (Table S2b). Average richness values were lower when the canopy was absent than when present, with differences between $\mathrm{C}+$ and $\mathrm{C}$ - treatments of 1.28 and 3.24 in Periods 3 and 4, respectively (cf. Fig. 2a for Period 4). Among periods, the grazer treatment affected richness differently between the enrichment treatments as shown by the significant Period $\times \mathrm{Gr} \times \mathrm{Nu}$ interaction (Table S2b, Fig. 2b). Diversity was significantly affected by the grazer treatment in presence of a canopy in Periods 3 and 4, with higher values in grazer-reduced plots (illustrated in Fig. 2c for Period 4, see also Table 1).

In contrast to total abundance as \% cover, total abundance as biomass was significantly affected by the canopy treatment (Table 1). When the canopy was removed, more than half of the total biomass of associated taxa disappeared (Fig. 2d), with an average of $95 \%$ attributed to a loss of mussel biomass.

When the associated community was separated into 2 groups (understorey algae and invertebrates) and compared with respect to total abundance (\% cover) and richness in Period 4, understorey algae had a higher cover when the canopy was absent (Fig. 3a; Student's $t$-test, $t=-3.0, \mathrm{p}=0.016$ ) but had similar species richness ( $t=0.71, \mathrm{p}=0.482$, with only $R$. clavata present). Invertebrates were more abundant $(t=2.0 \mathrm{p}=0.05)$ and had higher richness $(t=6.73$, $\mathrm{p}<0.0001$ ) when a canopy was present (Fig. 3a,b).

\section{Community structure}

All communities in the experimental plot categories were similar prior to the start of the experiment (Period 1). The canopy treatment significantly affected the associated community structure 
Table 1. Summary of ANOVAs showing the effects of canopy (Ca), grazer (Gr) and nutrient enrichment (Nu) treatments and the crossed factors on \% cover, richness, Simpson's index of diversity, and biomass of the associated species of the community for all periods (only Period 4 for biomass). Significant values are shown in bold. For an explanation of periods see 'Materials and methods: Sampling'

\begin{tabular}{|c|c|c|c|c|c|c|c|c|c|}
\hline & \multirow[t]{2}{*}{$\mathrm{df}$} & \multicolumn{2}{|c|}{ Period 1} & \multicolumn{2}{|c|}{ Period 2} & \multicolumn{2}{|c|}{ Period 3} & \multicolumn{2}{|c|}{ Period 4} \\
\hline & & $F$-ratio & $\mathrm{p}$ & F-ratio & $\mathrm{p}$ & $F$-ratio & $\mathrm{p}$ & F-ratio & $\mathrm{p}$ \\
\hline \multicolumn{10}{|l|}{$\%$ Cover } \\
\hline $\mathrm{Ca}$ & 1 & 0.167 & 0.686 & 0.006 & 0.937 & 1.06 & 0.314 & 0.257 & 0.617 \\
\hline $\mathrm{Gr}$ & 1 & 0.216 & 0.647 & 4.63 & 0.042 & 0.948 & 0.340 & 0.261 & 0.614 \\
\hline $\mathrm{Nu}$ & 1 & 1.658 & 0.210 & 0.006 & 0.940 & 0.080 & 0.779 & 0.620 & 0.439 \\
\hline $\mathrm{Ca} \times \mathrm{Gr}$ & 1 & 0.654 & 0.427 & 0.221 & 0.643 & 0.132 & 0.720 & 0.457 & 0.505 \\
\hline $\mathrm{Ca} \times \mathrm{Nu}$ & 1 & 0.324 & 0.575 & 1.686 & 0.207 & 0.262 & 0.614 & 1.633 & 0.214 \\
\hline $\mathrm{Gr} \times \mathrm{Nu}$ & 1 & 0.000 & 0.988 & 0.701 & 0.411 & 0.366 & 0.551 & 1.481 & 0.236 \\
\hline $\mathrm{Ca} \times \mathrm{Gr} \times \mathrm{Nu}$ & 1 & 0.009 & 0.927 & 2.892 & 0.102 & 2.2607 & 0.146 & 0.293 & 0.593 \\
\hline Residual & 24 & & & & & & & & \\
\hline Corrected total & 31 & & & & & & & & \\
\hline \multicolumn{10}{|l|}{ Richness } \\
\hline $\mathrm{Ca}$ & 1 & 5.765 & 0.025 & 1.852 & 0.186 & 12.741 & 0.002 & 47.61 & $<0.0001$ \\
\hline $\mathrm{Gr}$ & 1 & 0.471 & 0.499 & 0.000 & 1.000 & 0.318 & 0.578 & 0.831 & 0.371 \\
\hline $\mathrm{Nu}$ & 1 & 0.118 & 0.735 & 0.074 & 0.788 & 0.035 & 0.853 & 0.017 & 0.898 \\
\hline $\mathrm{Ca} \times \mathrm{Gr}$ & 1 & 4.235 & 0.051 & 1.852 & 0.186 & 0.882 & 0.357 & 0.831 & 0.371 \\
\hline $\mathrm{Ca} \times \mathrm{Nu}$ & 1 & 0.118 & 0.735 & 0.000 & 1.000 & 0.882 & 0.357 & 2.051 & 0.165 \\
\hline $\mathrm{Gr} \times \mathrm{Nu}$ & 1 & 0.000 & 1.000 & 3.63 & 0.069 & 0.318 & 0.578 & 8.966 & 0.006 \\
\hline $\mathrm{Ca} \times \mathrm{Gr} \times \mathrm{Nu}$ & 1 & 1.882 & 0.183 & 0.296 & 0.591 & 0.318 & 0.578 & 0.017 & 0.898 \\
\hline Residual & 24 & & & & & & & & \\
\hline Corrected total & 31 & & & & & & & & \\
\hline \multicolumn{10}{|l|}{ Diversity } \\
\hline $\mathrm{Ca}$ & 1 & 6.626 & 0.017 & 0.012 & 0.914 & 3.296 & 0.082 & 0.540 & 0.470 \\
\hline $\mathrm{Gr}$ & 1 & 0.058 & 0.812 & 0.269 & 0.608 & 0.571 & 0.457 & 5.875 & 0.023 \\
\hline $\mathrm{Nu}$ & 1 & 0.032 & 0.859 & 0.303 & 0.587 & 0.099 & 0.756 & 0.278 & 0.603 \\
\hline $\mathrm{Ca} \times \mathrm{Gr}$ & 1 & 0.176 & 0.679 & 2.850 & 0.104 & 5.183 & 0.032 & 6.566 & 0.017 \\
\hline $\mathrm{Ca} \times \mathrm{Nu}$ & 1 & 1.698 & 0.205 & 1.523 & 0.229 & 0.210 & 0.651 & 0.123 & 0.729 \\
\hline $\mathrm{Gr} \times \mathrm{Nu}$ & 1 & 0.078 & 0.782 & 0.207 & 0.653 & 0.414 & 0.526 & 0.229 & 0.637 \\
\hline $\mathrm{Ca} \times \mathrm{Gr} \times \mathrm{Nu}$ & 1 & 0.264 & 0.612 & 0.345 & 0.562 & 0.081 & 0.778 & 0.300 & 0.589 \\
\hline Residual & 24 & & & & & & & & \\
\hline Corrected total & 31 & & & & & & & & \\
\hline \multicolumn{10}{|l|}{ Biomass } \\
\hline $\mathrm{Ca}$ & 1 & & & & & & & 14.697 & 0.001 \\
\hline $\mathrm{Gr}$ & 1 & & & & & & & 1.217 & 0.281 \\
\hline $\mathrm{Nu}$ & 1 & & & & & & & 0.698 & 0.412 \\
\hline $\mathrm{Ca} \times \mathrm{Gr}$ & 1 & & & & & & & 2.067 & 0.163 \\
\hline $\mathrm{Ca} \times \mathrm{Nu}$ & 1 & & & & & & & 0.292 & 0.594 \\
\hline $\mathrm{Gr} \times \mathrm{Nu}$ & 1 & & & & & & & 0.002 & 0.965 \\
\hline $\mathrm{Ca} \times \mathrm{Gr} \times \mathrm{Nu}$ & 1 & & & & & & & 1.017 & 0.323 \\
\hline Error & 24 & & & & & & & & \\
\hline Corrected total & 31 & & & & & & & & \\
\hline
\end{tabular}

(Pseudo- $F_{1,24}=5.008, \mathrm{p}=0.004 ;$ Table 2 ) only $50 \mathrm{~d}$ after the start of the experiment (Period 3), with differences remaining significant until the end of the experiment (Period 4; Fig. 4a). This effect was also detected in the biomass structure (Table 2, Fig. 4b). The associated community abundance structure (either as \% cover or biomass) was not affected by the grazer or by the nutrient enrichment treatments. We observed similar results in compositional structure (all abundances transformed into presenceabsence, results not shown). The composition changed between periods, and a significant effect of canopy treatment was observed in Periods 3 and 4 , but no effect from either the grazer or nutrient enrichment treatments was observed.

Of all treatments (individual or in combination), those that included the canopy treatment had greater average dissimilarities over time when compared to the natural assemblages (i.e. control plots) (Fig. 5). Four weeks after the start of the experiments (Period 2), dissimilarities between the control plots and all other treatments had generally increased. 

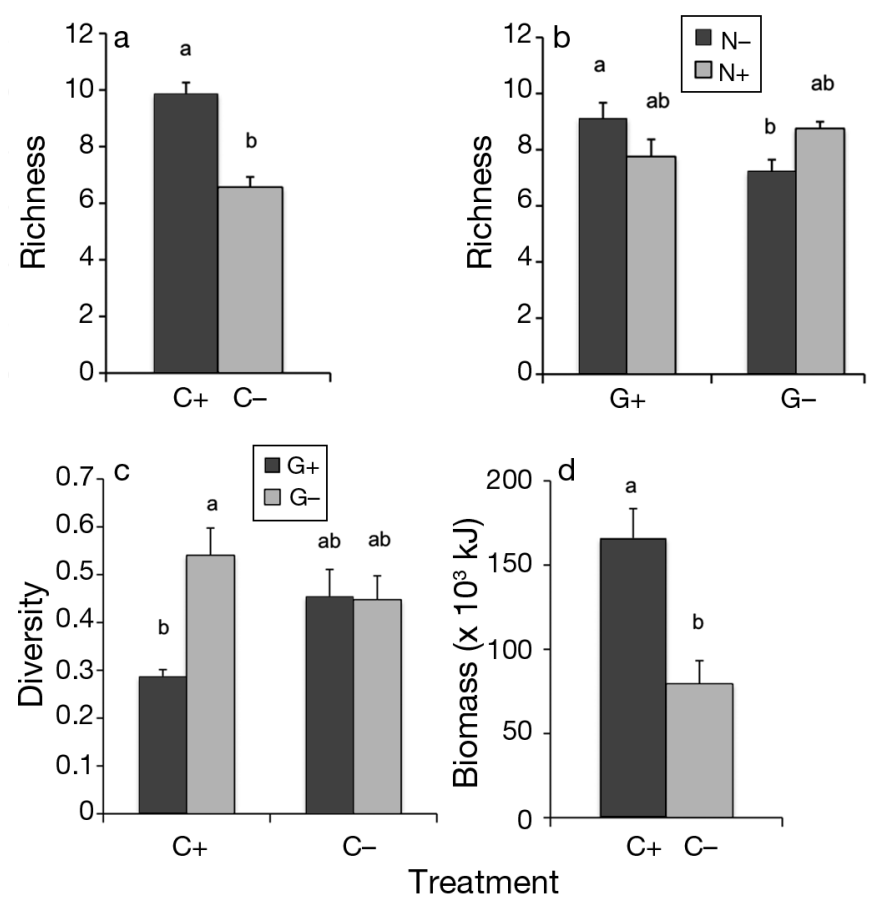

Fig. 2. Mean $( \pm \mathrm{SE})$ values of $(\mathrm{a}, \mathrm{b})$ species richness, (c) Simpson's diversity index and (d) biomass among the various treatments. Values in (c) are pooled data from Periods 2 to 4 , while values in (a), (b) and (d) are only from the end of the experiment (i.e. Period 4). Black and gray bars are the respective treatments with $\mathrm{C}+$ : canopy present; $\mathrm{C}-$ : canopy removed; $\mathrm{G}+$ : grazers present; $\mathrm{G}-$ : number of grazers reduced; $\mathrm{N}+$ : nutrients added; N-: no nutrients added. See Fig. 1 for details. Number of replicates used to obtain averages: $\mathrm{n}=16$ in (a) and (d); $\mathrm{n}=8$ in (b); and $\mathrm{n}=24$ in (c). Different lowercase letters indicate significant differences $(p<0.05)$

Only after 2 mo (Period 3) did the treatments with the canopy treatment (i.e. CG, CGN, C and CN) become significantly more dissimilar from the natural communities, while the other treatments (i.e. N, G and GN) became more similar to the control plots over time (smaller dissimilarity). At the end of the experiment, larger dissimilarities (compared to controls) were observed with the C, CG and CGN treatments (Fig. 5). In Period 3, the main species causing $90 \%$ of the dissimilarity were the mussels Mytilus spp., the encrusting algae $R$. clavata and the sea anemone Aulactinaria stella. In Period 4, those same species still accounted for the dissimilarities with an addition of Polychaeta and Oligochaeta.

For the community structure expressed in biomass, $\mathrm{C}$ - treatments were significantly more dissimilar from the natural communities; CG and CGN treatments had the highest dissimilarities (Fig. 6).

The grazer treatment using cageless techniques failed to significantly reduce the abundance (in \% cover and biomass) of grazer species except for the

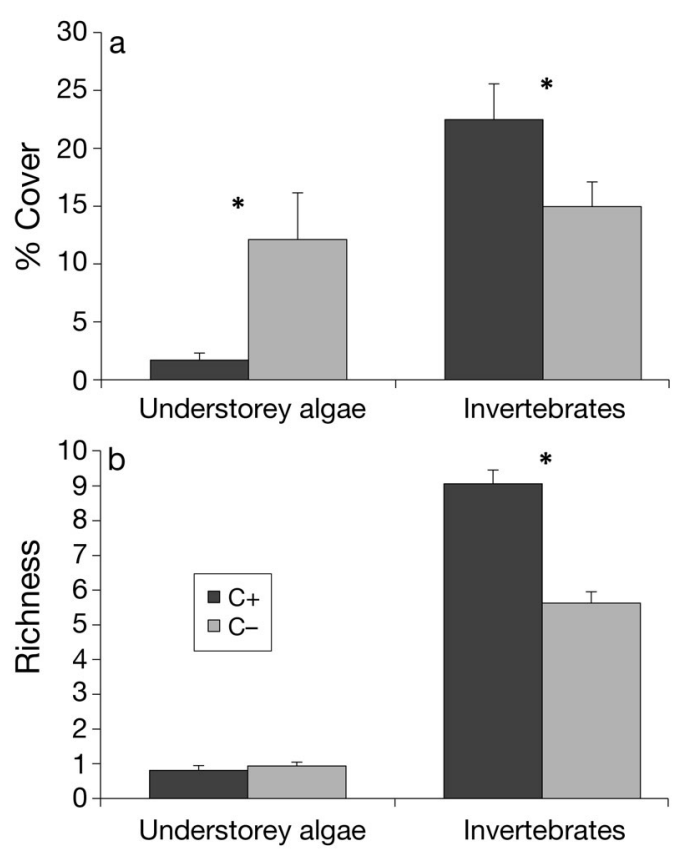

Fig. 3. Average $( \pm \mathrm{SE})(\mathrm{a}) \%$ cover and (b) richness $(\mathrm{n}=16)$ of understorey algae and invertebrates (without grazers) among the canopy treatment in Period 4 (black bars: canopy present; gray bars: canopy absent). $\left({ }^{*}\right)$ indicates significant differences; see legend of Fig. 1 for further details of treatments

first month of the experiment (results not shown). Yet the abundances were reduced for several days (up to 4 out of 9 or $10 \mathrm{~d}$; L. Joseph, M. Cusson and S. Cimon unpubl. data). The non-accessibility of the plots at high tides constrained constant removal and thus meant that low abundance could not always be maintained.

A closer examination of the canopy removal effect on grazers (i.e. those that were not considered as part of the associated species in all other analyses) illustrated that the absence of canopy (only in G+ treatment plots) had a significantly negative effect on the abundance of L. obtusata and Jaera marina (reduction of 94 and $95 \%$, respectively), but was not significant for Mytilus spp. (31\%). In contrast, it had a positive effect on the average abundance of the gastropods L. saxatilis and L. littorea (increase of 87 and $100 \%$, respectively) as well as for the encrusting algae $R$. clavata, which increased its percentage cover by 6 -fold when the canopy was absent. Using the biomass structure data, the absence of canopy had a significantly negative effect on the biomass of L. obtusata and J. marina (98\% respectively), and Mytilus spp. (49\%), although the biomass of L. saxatilis and L. littorea increased when the canopy was removed (increase of 53 and 100\%, respectively). 
Table 2. Summary of PERMANOVAs showing the effects of canopy (Ca), grazer (Gr) and enrichment (Nu) treatments along with the crossed factors on the structure in abundance in \% cover and biomass of the associated species of the communities for all periods (only Period 4 for biomass). Data were square-root transformed for \% cover and fourth-root transformed for biomass prior to estimating the Bray-Curtis similarities. Significant values are shown in bold

\begin{tabular}{|c|c|c|c|c|c|c|c|c|c|}
\hline & \multirow[t]{2}{*}{ df } & \multicolumn{2}{|c|}{ Period 1} & \multicolumn{2}{|c|}{ Period 2} & \multicolumn{2}{|c|}{ Period 3} & \multicolumn{2}{|c|}{ Period 4} \\
\hline & & Pseudo- $F$ & $\mathrm{p}$ & Pseudo- $F$ & $\mathrm{p}$ & Pseudo- $F$ & $\mathrm{p}$ & Pseudo- $F$ & $\mathrm{p}$ \\
\hline \multicolumn{10}{|l|}{$\%$ Cover } \\
\hline $\mathrm{Ca}$ & 1 & 1.971 & 0.117 & 0.774 & 0.525 & 5.008 & 0.004 & 9.536 & 0.001 \\
\hline $\mathrm{Gr}$ & 1 & 1.814 & 0.152 & 2.085 & 0.118 & 0.869 & 0.452 & 1.279 & 0.312 \\
\hline $\mathrm{Nu}$ & 1 & 0.591 & 0.608 & 0.983 & 0.401 & 0.440 & 0.735 & 0.224 & 0.894 \\
\hline $\mathrm{Ca} \times \mathrm{Gr}$ & 1 & 0.285 & 0.848 & 0.710 & 0.584 & 1.604 & 0.196 & 1.216 & 0.297 \\
\hline $\mathrm{Ca} \times \mathrm{Nu}$ & 1 & 0.431 & 0.717 & 1.089 & 0.376 & 0.254 & 0.859 & 1.373 & 0.260 \\
\hline $\mathrm{Gr} \times \mathrm{Nu}$ & 1 & 0.760 & 0.499 & 0.767 & 0.515 & 0.435 & 0.717 & 1.254 & 0.305 \\
\hline $\mathrm{Ca} \times \mathrm{Gr} \times \mathrm{Nu}$ & 1 & 0.899 & 0.435 & 0.707 & 0.581 & 0.279 & 0.834 & 0.469 & 0.735 \\
\hline Residual & 24 & & & & & & & & \\
\hline Total & 31 & & & & & & & & \\
\hline \multicolumn{10}{|l|}{ Biomass } \\
\hline $\mathrm{Ca}$ & 1 & & & & & & & 21.614 & 0.001 \\
\hline $\mathrm{Gr}$ & 1 & & & & & & & 0.767 & 0.556 \\
\hline $\mathrm{Nu}$ & 1 & & & & & & & 1.357 & 0.230 \\
\hline $\mathrm{Ca} \times \mathrm{Gr}$ & 1 & & & & & & & 1.313 & 0.270 \\
\hline $\mathrm{Ca} \times \mathrm{Nu}$ & 1 & & & & & & & 0.272 & 0.899 \\
\hline $\mathrm{Gr} \times \mathrm{Nu}$ & 1 & & & & & & & 0.585 & 0.719 \\
\hline $\mathrm{Ca} \times \mathrm{Gr} \times \mathrm{Nu}$ & 1 & & & & & & & 0.376 & 0.842 \\
\hline Residual & 24 & & & & & & & & \\
\hline Total & 31 & & & & & & & & \\
\hline
\end{tabular}

\section{Community function}

Nutrient enrichment and canopy treatments had no effect on NPP $\left(\chi^{2}=6.67, \mathrm{p}=0.083\right)$ or $R\left(\chi^{2}=4.36, \mathrm{p}=\right.$ 0.225) (Fig. 7), while for GPP there was a difference observed for the canopy treatment but no effect from nutrient enrichment $\left(\chi^{2}=8.13, \mathrm{p}=0.044\right)$ (Fig. 7). However, when the canopy was removed, we observed only very small values of NPP and GPP for the communities. Only positive $\mathrm{CO}_{2}$ fluxes were observed (Fig. 7) for C-treatments, meaning that the productivity of the understorey algae species was negligible compared to the respiration of heterotrophic organisms.

\section{DISCUSSION}

Our study showed that, taken in isolation, canopy loss was the strongest single effect affecting community structure and functioning, while community resistance was observed when grazers were reduced and nutrients were added. When these 3 factors were added together, various trends emerged, suggesting a lower resistance of the community when facing multiple stressors.

\section{Resistance of the community}

High resistance of the benthic community to nutrient enrichment and periodic grazer reduction was observed in this study. The absence of canopy, on the contrary, strongly affected the resistance of the associated species. Undoubtedly, the canopy macroalgae played a key role in the stability of the structure and function of the benthic community. Interestingly, the effects of the absence of canopy appeared only after 2 mo of treatment, indicating temporary resistance most likely due to the large number of Fucus spp. juveniles that appeared and grew fast as part of an initial resilience (with an average cover of $41 \pm 24 \%$ ), perhaps still providing some protection for the understorey species. This 'pulse' perturbation (after a single event; Bender et al. 1984) was not enough to induce change; maintaining the removal longer, or applying a 'press' perturbation, provoked change. One month after impact, communities in all treatments increased their dissimilarity from the controls. However, $\mathrm{C}+$ treatments thereafter decreased in dissimilarity, while most $\mathrm{C}$ - treatments continued to increase their dissimilarities. This suggests less resistance to canopy removal (i.e. Fig. 5). 

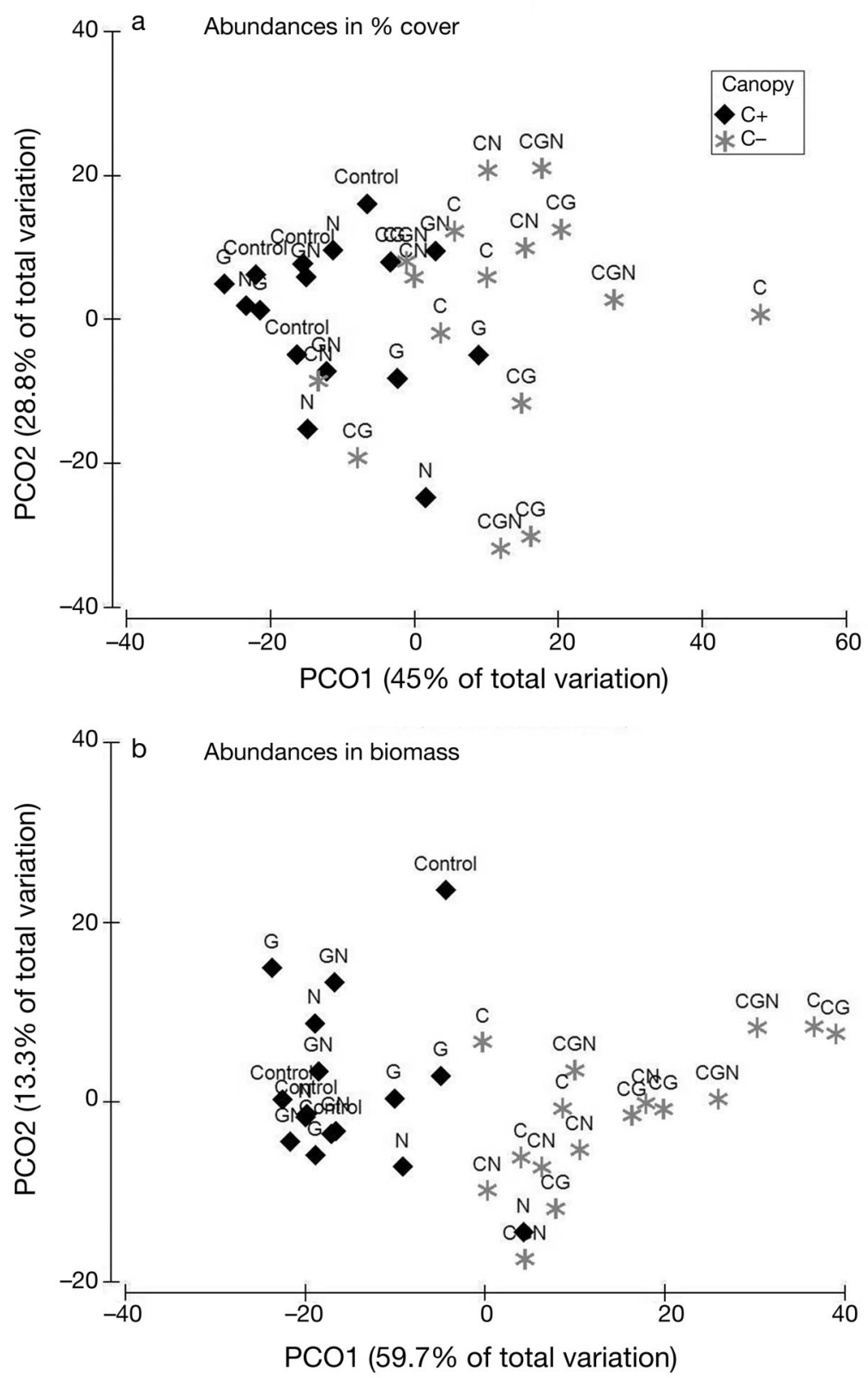

Fig. 4. Principal coordinate analysis (PCO) ordinations illustrating the effect of canopy treatment $(*$ canopy present; $*=$ canopy absent) during Period 4 on the community structure of the associated species in (a) \% cover, square-root transformed, and in (b) biomass, fourth-root transformed. See Fig. 1 for treatments and definition of $C, G, N$; number of letters in the treatment labels represents the quantity of stress applied

action, etc.) for the understorey species (Bertness et al. 1999, see also stress as 'lateral modifiers' in Thompson et al. 2004). We often observed temperatures that were $>10^{\circ} \mathrm{C}$ higher on substrates when the canopy was removed (measured by an infra-red camera; data not shown). The presence of the canopy cover may increase richness and diversity by improving conditions, as shown by Schiel \& Lilley $(2007,2011)$ and Watt \& Scrosati (2013). Settling species need to overcome the physical impacts of wave action, higher temperatures and whiplash (Lewis 1964, Hawkins 1983). For example, whiplash by surrounding algae and higher temperatures (i.e. desiccation) can lead to a decrease in recruitment and growth of algal propagules (Kiirikki 1996, Kim \& DeWreede 1996) and to a higher mortality rate of settling species (Hawkins 1983, Kim \& DeWreede 1996). Canopy loss may lead to bleaching of algae and the reduction of invertebrates due to their exposition to light, elevated temperatures and wave action (Jenkins et al. 1999a,b, Cervin et al. 2004). When the canopy was removed, more understorey algae (especially encrusting algae Ralfsia clavata) and fewer invertebrates were observed (cf. Fig. 3), confirming the findings of the above-cited literature. In our study, canopy absence reduced species richness and negatively affected diversity, but only in the absence of grazers. In addition, the reduced abundance of invertebrates (cf. Fig. 3) with canopy loss might also be caused by lower food supply. Littorina obtusata, the dominant grazer in the presence of a canopy, was replaced by L. saxatilis when the canopy was removed. This change could be explained by their feeding habits, since although both L. obtusata and L. sax-

\section{Effects on community structure}

The absence of canopy reduced species richness and affected the entire structure of the associated (unmanipulated) species abundance, both in terms of $\%$ cover and biomass. The loss of Fucus spp. as a habitat-forming species resulted in less facilitation and an increased stress level (e.g. temperature, wave atilis feed on Fucus spp. (Watson \& Norton 1987, Barker \& Chapman 1990), L. saxatilis also feeds on rocky surface biofilms (Sacchi et al. 1977).

The open space created by the removal of the canopy may be colonized by other species such as turf-forming or ephemeral algae (Sousa 1979, McCook \& Chapman 1993). In our study, however, only $R$. clavata benefitted from the absence of the 


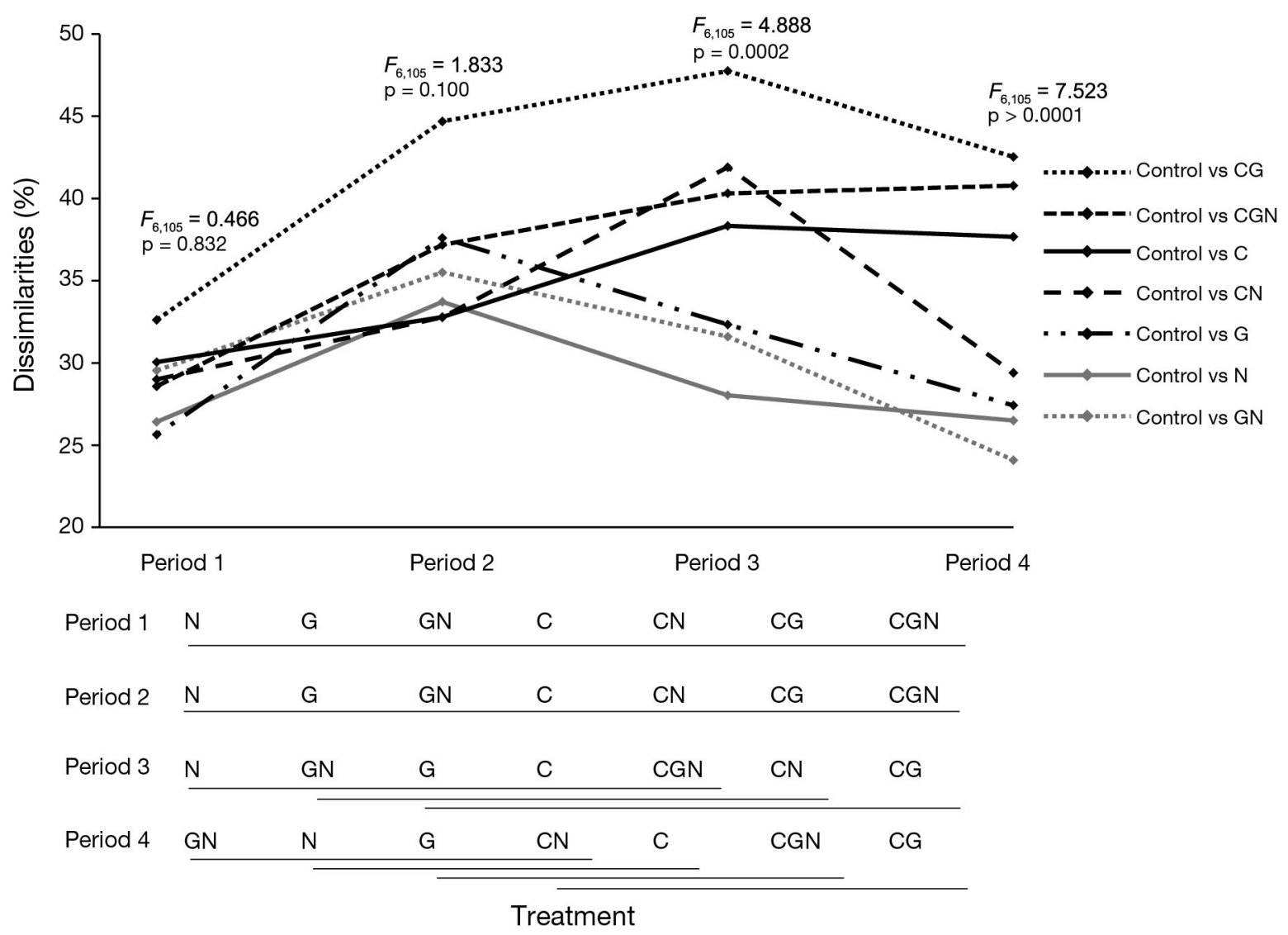

Fig. 5. Average dissimilarities $(n=16)$ between pairs of control and treatments plots in each period for abundance in $\%$ cover of the associated species. In the matrix below the graph, treatments underlined with the same line are not significantly different $(p<0.05)$. See Fig. 1 for treatments and definition of $C, G, N$; number of letters in the treatment labels represents the quantity of stress applied

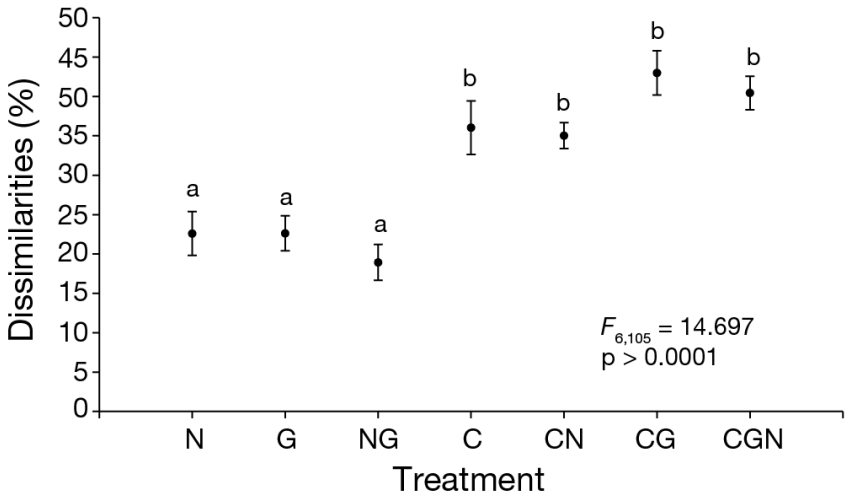

Fig. 6. Mean $( \pm \mathrm{SE})$ dissimilarities $(\mathrm{n}=16)$ between pairs of control and other treatment plots in terms of biomass structure of the associated species in Period 4. See Fig. 1 for treatments and definition of $C, G, N_{i}$ number of letters in the treatment labels reflects the number of stressors applied. Lowercase letters indicate significant differences (ANOVA test of dissimilarities, $\mathrm{p}<0.05$ ) canopy by extending its cover (cf. Fig. 3). Propagule availability (Sousa 1984) and the timing of treatment initiation in the season (Archambault \& Bourget 1983) are critical for recolonization. Even though Fucus spp. recruitment occurs primarily during the summer (Archambault \& Bourget 1983, Lamote \& Johnson 2008), the delayed start of our experiments (late spring) combined with a lack of efficient grazer exclusion probably explain the lack of ephemeral algae. However, Archambault \& Bourget (1983) observed rapid colonization of substrate by ephemeral algae after removing the canopy over the same period of the year and in the same region as our study. In the St. Lawrence Estuary, the abundance of ephemeral algae may vary among years, as very few species were observed in our study whereas 1 yr later (i.e. summer 2013), Porphyra spp. were very abundant with fewer fucoid juveniles (authors' pers. obs.).

No proliferation of ephemeral algae was observed in our study, although ephemeral species (e.g. Por- 


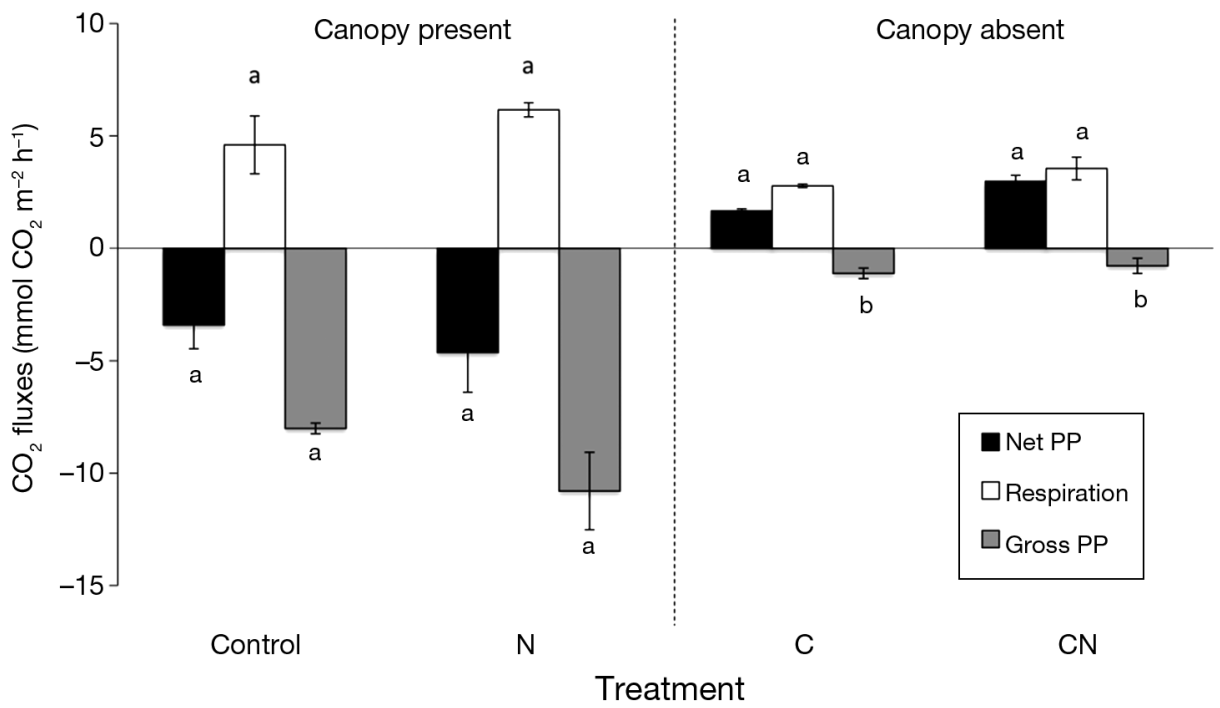

Fig. 7. Average ( \pm SE) community net primary production (Net PP; black bars), respiration $\left(R_{i}\right.$ white bars) and gross primary production (Gross PP; gray bars) when canopy is present (left; $\mathrm{n}=3$ ) and when canopy is removed (right; $\mathrm{n}=2$ ). See Fig. 1 for treatments and abbreviations; number of letters in the treatment labels reflects the number of stressors applied. Lowercase letters indicate significant differences $(p<$ 0.05 ) within each variable

phyra spp., Ulva spp. and Chordaria spp.) may be abundant in the lower part of the intertidal zone. The reduced grazer treatment in our study led to increased diversity. This seemed to be mainly caused by a small evenness $\left(J^{\prime}\right)$ in the G+ treatments due to the dominance of the mussels Mytilus spp. (results not shown). Other species accounted for the difference in diversity as the encrusted algae $R$. clavata, the polychaetes Nereis spp. and the sea anemone Aulactinia stella were more abundant in the treatments when grazers were reduced. This observation is, however, difficult to explain, as grazer treatment effects are mainly expected on algae and not on invertebrates. The fact that our grazer treatment was not as efficient as we expected between maintenance sessions may explain the limited effects that were observed in our study. Sticky barriers have proven their efficiency reducing gastropods grazers in warmer environments (e.g. Australia: $10 \times 10 \mathrm{~cm}$ plots, Range et al. 2008; California: $10 \times 10 \mathrm{~cm}$ plots, Aquilino \& Stachowicz 2012). In our study, however, the large size of the exclusion $(50 \times 50 \mathrm{~cm})$ as well as the cold waters of the St. Lawrence Estuary may have reduced their efficiency.

Nitrogen is known to be a limiting nutrient for algae in marine habitats. High levels of nitrogen in water are used by algae for growth (Wheeler \& North 1980) or storage (Chapman \& Craigie 1977). Ephemeral algae are fast-growing species and will therefore use nutrients more rapidly than perennial algae like fucoids (Duarte 1995). Although we observed higher nitrogen content in macroalgae, the enrichment treatment did not affect the associated benthic community either in richness or in structure, contrary to other studies. Indeed, higher nutrient availability may enhance algal richness and diversity (Worm et al. 2002, Korpinen et al. 2007) and increase the abundance of ephemeral algae (Johansson et al. 1998, Eriksson et al. 2007) and propagules or periphyton (Eriksson et al. 2006b), leading to a higher food supply for the associated community. An additional input of nutrients can modify the food preference of herbivores and change their competitive interactions with grazing shifts (Worm et al. 1999, Russell \& Connell 2005), thereby influencing the composition within the assemblage. Enrichment combined with canopy loss can lead to an increase in the abundance of macroalgae (Eriksson et al. 2007), or a shift in dominance towards opportunistic species and a decrease in the invertebrates that had a refuge in the canopy (Benedetti-Cecchi et al. 2001). Some studies have observed an increase in the abundance of either recruits or mature macroalgae with nutrient enrichment when grazers were reduced (Guerry 2008, Masterson et al. 2008). Others have shown that under nutrient-enriched conditions and in the absence of grazers, Fucus spp. failed to colonize the substrate and were outcompeted by fast-growing ephemeral algae; with grazers present, the opportunistic algae were less abundant (Korpinen et al. 2007, Korpinen \& Jormamailen 2008). Neither of these observations was found in our study. A delayed community response to nutrient input is possible. Kraufvelin et al. (2006) and Bokn et al. (2002) observed a delayed response (16 mo to $3 \mathrm{yr}$ ) of fucoid species to enrichment even though rapid (within a few months), relatively minor effects on the community structure were detected (increase of Ulva spp. and some grazers).

Although the grazer reduction treatment had almost no effect on our community abundance structure, when combined with the canopy treatment we 
observed, at the end of the experiment, a trend towards greater differences between control plots and plots with multiple treatments than between control plots and plots with single treatments (cf. Fig. 5). This suggests that multiple disturbances and stresses may act in synergy leading to stronger effects than when applied alone. This highlights the need to analyze interactions among treatments, as they might be important in field situations, and likewise, to allow enough time to pass for these treatments to take effect.

\section{Effects on ecosystem functioning}

It is known that macroalgae primary production can be positively affected by nutrient additions (Ylla et al. 2007, Krause-Jensen et al. 2012, but not in Kraufvelin et al. 2010). However, our results did not show an enrichment effect: primary production did not increase significantly even when nutrient storage was higher. On the other hand, we did observe a strong negative effect of canopy loss on GPP. With a community affected by canopy loss, changes in functioning were expected through lower abundance and low productivity of the understorey community (Gollety et al. 2008, Valdivia et al. 2012, Crowe et al. 2013). In our study, only $R$. clavata was present as crustose algae and its production was probably not sufficient to compensate for the respiration of other heterotrophic organisms present. The lack of increasing ephemeral algae led to a nonsignificant increase in total abundance and richness of understorey algae for enriched plots (data not shown), resulting in no increase in productivity.

\section{CONCLUSIONS}

In response to different disturbance or stress sources, a community may resist, or fail and change. The benthic communities in our study were not resistant to canopy loss, leading to significant changes in community structure and composition. Our study reconfirms the important role of the dominant habitat-forming species Fucus spp. in influencing the structure and function of their associated communities. Following enrichment and grazer reduction, the marine benthic communities of the mid-intertidal zone of the St. Lawrence Estuary remained largely unaffected. Grazer reduction combined with other treatments provoked various responses with effects on the structure in terms of abundance (both \% cover and biomass) but with little or no effect on richness, diversity and total abundances. Therefore, in this assemblage, habitat-forming species have a stronger effect than bottom-up forcing and top-down controls. Moreover, our study also provided new insight into possible interactions among treatments, highlighting the importance of testing for potential synergetic or antagonistic effects of multiple stresses. Natural coastal communities often face multiple threats. Therefore, understanding the antagonistic and additive effects of stresses may help identify the ecological mechanisms that solicit shifts in community structure and function. Studying these interactions will also help policy managers establish mitigation and conservation priorities.

Acknowledgements. We thank S. Cimon, J. Lemieux, D. A. Gauthier, S. Lavoie, G. Grosbois and G. Larocque, who helped in the field maintaining treatments throughout the course of the experiment. Thanks to Dr. M. B. Hay for verifying the English. We thank 3 anonymous reviewers for providing constructive comments and critiques on the final version. The project is a contribution to the research program of Québec-Océan. Financial support was provided by grants from FRQNT (Quebec Funds for Research in Nature and Technology, New University Researchers Start-up Program) and Natural Sciences and Engineering Research Council of Canada (NSERC; Discovery Grants) to M.C.

\section{LITERATURE CITED}

Åberg P (1992) A demographic study of two populations of the seaweed Ascophyllum nodosum. Ecology 73: 1473-1487

Airoldi L, Beck MW (2007) Loss, status and trends for coastal marine habitats of Europe. Oceanogr Mar Biol Annu Rev 45:345-405

Allen JR, Slinn DJ, Shammon TM, Hartnoll RG, Hawkins SJ (1998) Evidence for eutrophication of the Irish sea over four decades. Limnol Oceanogr 43:1970-1974

> Anderson MJ, Underwood AJ (1997) Effects of gastropod grazers on recruitment and succession of an estuarine assemblage: a multivariate and univariate approach. Oecologia 109:442-453

Anderson MJ, Gorley RN, Clarke KR (2008) PERMANOVA+ for PRIMER: guide to software and statistical methods. PRIMER-E, Plymouth

Aquilino KM, Stachowicz JJ (2012) Seaweed richness and herbivory increase rate of community recovery from disturbance. Ecology 93:879-890

Archambault D, Bourget E (1983) Importance du régime de dénudation sur la structure et la succession des communautés intertidales de substrats rocheux en milieu subarctique. Can J Fish Aquat Sci 40:1278-1292

- Barker KM, Chapman ARO (1990) Feeding preferences of periwinkles among 4 species of Fucus. Mar Biol 106: 113-118

> Bender EA, Case TJ, Gilpin ME (1984) Perturbation experiments in community ecology: theory and practice. Ecology $65: 1-13$ 
Benedetti-Cecchi L, Pannacciulli F, Bulleri F, Moschella PS, Airoldi L, Relini G, Cinelli F (2001) Predicting the consequences of anthropogenic disturbance: large-scale effects of loss of canopy algae on rocky shores. Mar Ecol Prog Ser 214:137-150

Bergeron P, Bourget E (1984) Effet du froid et des glaces sur les peuplements intertidaux des régions nordiques, particulièrement dans l'estuaire du Saint-Laurent. Oceanis 10:279-304

> Bertness MD, Leonard GH (1997) The role of positive interactions in communities: lessons from intertidal habitats. Ecology 78:1976-1989

> Bertness MD, Leonard GH, Levine JM, Schmidt PR, Ingraham AO (1999) Testing the relative contribution of positive and negative interactions in rocky intertidal communities. Ecology 80:2711-2726

Bokn TL, Moy FE, Christie H, Engelbert S and others (2002) Are rocky shore ecosystems affected by nutrientenriched seawater? Some preliminary results from a mesocosm experiment. Hydrobiologia 484:167-175

Brey T, Müller-Wiegmann C, Zittier ZMC, Hagen W (2010) Body composition in aquatic organisms - a global data bank of relationships between mass, elemental composition and energy content. J Sea Res 64:334-340

Bulleri F, Benedetti-Cecchi L, Acunto S, Cinelli F, Hawkins SJ (2002) The influence of canopy algae on vertical patterns of distribution of low-shore assemblages on rocky coasts in the northwest Mediterranean. J Exp Mar Biol Ecol 267:89-106

Cervin G, Lindegarth M, Viejo RM, Aberg P (2004) Effects of small-scale disturbances of canopy and grazing on intertidal assemblages on the Swedish west coast. J Exp Mar Biol Ecol 302:35-49

Chapman ARO, Craigie JS (1977) Seasonal growth in Laminaria longicruris: relations with dissolved inorganic nutrients and internal reserves of nitrogen. Mar Biol 40: 197-205

Clark KR, Gorley RN (2006) PRIMER v6: user manual/ tutorial. PRIMER-E, Plymouth

> Crowe TP, Frost NJ, Hawkins SJ (2011) Interactive effects of losing key grazers and ecosystem engineers vary with environmental context. Mar Ecol Prog Ser 430:223-234

> Crowe TP, Cusson M, Bulleri F, Davoult D and others (2013) Large-scale variation in combined impacts of canopy loss and disturbance on community structure and ecosystem functioning. PLoS ONE 8:e66238

> Duarte CM (1995) Submerged aquatic vegetation in relation to different nutrient regimes. Ophelia 41:87-112

Elton CS (1958) The ecology of invasions by animals and plants. University of Chicago Press, Chicago, IL

> Eriksson BK, Rubach A, Hillebrand H (2006a) Biotic habitat complexity controls species diversity and nutrient effects on net biomass production. Ecology 87:246-254

Eriksson BK, Rubach A, Hillebrand H (2006b) Community dominance by a canopy species controls the relationship between macroalgal production and species richness. Limnol Oceanogr 51:1813-1818

Eriksson BK, Rubach A, Hillebrand H (2007) Dominance by a canopy forming seaweed modifies resource and consumer control of bloom-forming macroalgae. Oikos 116: 1211-1219

Fradette P, Bourget E (1980) Ecology of benthic epifauna of the Estuary and Gulf of St. Lawrence: factors influencing their distribution and abundance on buoys. Can J Fish Aquat Sci 37:979-999
Gilbert D, Chabot D, Archambault P, Rondeau B, Hébert S (2007) Appauvrissement en oxygène dans les eaux profondes du Saint-Laurent marin. Nat Can 131:67-75

Gollety C, Migne A, Davoult D (2008) Benthic metabolism on a sheltered rocky shore: role of the canopy in the carbon budget. J Phycol 44:1146-1153

> Grime JP (1997) Biodiversity and ecosystem function: the debate deepens. Science 277:1260-1261

- Grimm V, Wissel C (1997) Babel, or the ecological stability discussions: an inventory and analysis of terminology and a guide for avoiding confusion. Oecologia 109: 323-334

Guerry AD (2008) Interactive effects of grazing and enrichment on diversity; conceptual implications of a rocky intertidal experiment. Oikos 117:1185-1196

Hanski I (2005) The shrinking world: ecological consequences of habitat loss. In: Kinne O (ed) Excellence in ecology, Book 14. International Ecology Institute, Oldendorf/Luhe

> Hawkins SJ (1983) Interactions of Patella and macroalgae with settling Semibalanus balanoides (L). J Exp Mar Biol Ecol 71:55-72

> Hawkins SJ, Harkin E (1985) Preliminary canopy removal experiments in algal dominated communities low on the shore and in the shallow subtital on the Isle of Man. Bot Mar 28:223-230

Hawkins SJ, Hartnoll RG (1983) Grazing of intertidal algae by marine invertebrates. Oceanogr Mar Biol Annu Rev 21:195-282

> Hawkins SJ, Sugden HE, Mieszkowska N, Moore PJ and others (2009) Consequences of climate-driven biodiversity changes for ecosystem functioning of North European rocky shores. Mar Ecol Prog Ser 396:245-259

Hooper DU, Chapin FS, Ewel JJ, Hector A and others (2005) Effects of biodiversity on ecosystem functioning: a consensus of current knowledge. Ecol Monogr 75:3-35

> Hooper DU, Adair EC, Cardinale BJ, Byrnes JEK and others (2012) A global synthesis reveals biodiversity loss as a major driver of ecosystem change. Nature 486:105-108

Jenkins SR, Hawkins SJ, Norton TA (1999a) Direct and indirect effects of a macroalgal canopy and limpet grazing in structuring a sheltered inter-tidal community. Mar Ecol Prog Ser 188:81-92

Jenkins SR, Hawkins SJ, Norton TA (1999b) Interaction between a fucoid canopy and limpet grazing in structuring a low shore intertidal community. J Exp Mar Biol Ecol 233:41-63

> Jenkins SR, Coleman RA, Della Santina P, Hawkins SJ, Burrows MT, Hartnoll RG (2005) Regional scale differences in the determinism of grazing effects in the rocky intertidal. Mar Ecol Prog Ser 287:77-86

Jochum M, Schneider FD, Crowe TP, Brose U, O'Gorman EJ (2012) Climate-induced changes in bottom-up and topdown processes independently alter a marine ecosystem. Philos Trans R Soc Lond B Biol Sci 367:2962-2970

> Johansson G, Eriksson BK, Pedersen M, Snoeijs P (1998) Long-term changes of macroalgal vegetation in the Skagerrak area. Hydrobiologia 385:121-138

Jones CG, Lawton JH, Shachak M (1994) Organisms as ecosystem engineers. Oikos 69:373-386

> Kiirikki M (1996) Experimental evidence that Fucus vesiculosus (Phaeophyta) controls filamentous algae by means of the whiplash effect. Eur J Phycol 31:61-66

Kim JH, DeWreede RE (1996) Effects of size and season of disturbance on algal patch recovery in a rocky intertidal 
community. Mar Ecol Prog Ser 133:217-228

Korpinen S, Jormamailen V (2008) Grazing and nutrients reduce recruitment success of Fucus vesiculosus L. (Fucales: Phaeophyceae). Estuar Coast Shelf Sci 78: 437-444

Korpinen S, Jormalainen V, Honkanen T (2007) Effects of nutrients, herbivory and depth on the macroalgal community in the rocky sublittoral. Ecology 88:839-852

Kraufvelin P, Moy FE, Christie H, Bokn TL (2006) Nutrient addition to experimental rocky shore communities revisited: delayed responses, rapid recovery. Ecosystems 9: 1076-1093

> Kraufvelin P, Lindholm A, Pedersen MF, Kirkerud LA, Bonsdorff E (2010) Biomass, diversity and production of rocky shore macroalgae at two nutrient enrichment and wave action levels. Mar Biol 157:29-47

Krause-Jensen D, Markager S, Dalsgaard T (2012) Benthic and pelagic primary production in different nutrient regimes. Estuaries Coasts 35:527-545

Lamote M, Johnson LE (2008) Temporal and spatial variation in the early recruitment of fucoid algae: the role of microhabitats and temporal scales. Mar Ecol Prog Ser 368:93-102

Lehman CL, Tilman D (2000) Biodiversity, stability, and productivity in competitive communities. Am Nat 156: $534-552$

Lewis JR (1964) The ecology of rocky shores. English University Press, London

Loreau M, Naeem S, Inchausti P (2002) Biodiversity and ecosystem functioning: synthesis and perspectives. Oxford University Press, New York, NY

Lubchenco J (1983) Littorina and Fucus: effects of herbivores, substratum heterogeneity, and plant escapes during succession. Ecology 64:1116-1123

MacArthur R (1955) Fluctuations of animal populations and a measure of community stability. Ecology 36:533-536

Maggi E, Bertocci I, Vaselli S, Benedetti-Cecchi L (2009) Effects of changes in number, identity and abundance of habitat-forming species on assemblages of rocky seashores. Mar Ecol Prog Ser 381:39-49

- Martins GM, Thompson RC, Neto AI, Hawkins SJ, Jenkins SR (2010) Exploitation of intertidal grazers as a driver of community divergence. J Appl Ecol 47:1282-1289

Masterson P, Arenas FA, Thompson RC, Jenkins SR (2008) Interaction of top down and bottom up factors in intertidal rockpools: effects on early successional macroalgal community composition, abundance and productivity. J Exp Mar Biol Ecol 363:12-20

McCook LJ, Chapman ARO (1993) Community succession following massive ice-scour on a rocky intertidal shore: recruitment, competition and predation during early, primary succession. Mar Biol 115:565-575

McKindsey CW, Bourget E (2001) Diversity of a northern rocky intertidal community: the influence of body size and succession. Ecology 82:3462-3478

> McNeely JA (1992) The sinking ark: pollution and the worldwide loss of biodiversity. Biodivers Conserv 1:2-18

> Migné A, Davoult D, Spilmont N, Menu D, Boucher G, Gattuso JP, Rybarczyk H (2002) A closed-chamber $\mathrm{CO}_{2}$-flux method for estimating intertidal primary production and respiration under emersed conditions. Mar Biol 140: 865-869

Montgomery DC (1991) Design and analysis of experiments. John Wiley \& Sons, Toronto

> Naeem S, Thompson LJ, Lawler SP, Lawton JH, Woodfin RM
(1994) Declining biodiversity can alter the performance of ecosystems. Nature 368:734-736

Nixon S, Buckley B, Granger S, Bintz J (2001) Responses of very shallow marine ecosystems to nutrient enrichment. Hum Ecol Risk Assess 7:1457-1481

Paerl HW (1997) Coastal eutrophication and harmful algal blooms: importance of atmospheric deposition and groundwater as 'new' nitrogen and other nutrient sources. Limnol Oceanogr 42:1154-1165

$>$ Pimm SL (1984) The complexity and stability of ecosystems. Nature 307:321-326

Quinn G, Keough M (2002) Experimental design and data analysis for biologists. Cambridge University Press, Cambridge

> Range P, Chapman MG, Underwood AJ (2008) Field experiments with 'cageless' methods to manipulate grazing gastropods on intertidal rocky shores. J Exp Mar Biol Ecol 365:23-30

> Reed DC, Foster MS (1984) The effects of canopy shading on algal recruitment and growth in a giant kelp forest. Ecology 65:937-948

> Rueda JL, Marina P, Urra J, Salas C (2009) Changes in the composition and structure of a molluscan assemblage due to eelgrass loss in southern Spain (Alboran Sea). J Mar Biol Assoc UK 89:1319-1330

Russell BD, Connell SD (2005) A novel interaction between nutrients and grazers alters relative dominance of marine habitats. Mar Ecol Prog Ser 289:5-11

Sacchi CF, Testard P, Voltolina D (1977) Researchs on compared trophic spectra of Littorina saxatilis and Littorina nigrolineata from beach of Roscoff. Cah Biol Mar 18: 499-505

> Sandjensen K, Borum J (1991) Interactions among phytoplankton, periphyton, and macrophytes in temperate fresh-waters and estuaries. Aquat Bot 41:137-175

Savard JP, Bernatchez P, Morneau F, Saucier F and others (2008) Étude de la sensibilité des côtes et de la vulnérabilité des communautés du golfe du Saint-Laurent aux impacts des changements climatiques. Ouranos, Montréal

> Schiel DR, Lilley SA (2007) Gradients of disturbance to an algal canopy and the modification of an intertidal community. Mar Ecol Prog Ser 339:1-11

> Schiel DR, Lilley SA (2011) Impacts and negative feedbacks in community recovery over eight years following removal of habitat-forming macroalgae. J Exp Mar Biol Ecol 407:108-115

> Scrosati R, Knox A, Valdivia N, Molis M (2011) Species richness and diversity across rocky intertidal elevation gradients in Helgoland: testing predictions from an environmental stress model. Helgol Mar Res 65:91-102

> Sousa WP (1979) Experimental investigations of disturbance and ecological succession in a rocky intertidal algal community. Ecol Monogr 49:227-254

Sousa WP (1984) Intertidal mosaics: patch size, propagule availability, and spatially variable patterns of succession. Ecology 65:1918-1935

Tait LW, Schiel DR (2011) Dynamics of productivity in naturally structured macroalgal assemblages: importance of canopy structure on light-use efficiency. Mar Ecol Prog Ser 421:97-107

- Thibodeau B, de Vernal A, Mucci A (2006) Recent eutrophication and consequent hypoxia in the bottom waters of the lower St. Lawrence Estuary: micropaleontological and geochemical evidence. Mar Geol 231:37-50

Thompson RC, Norton TA, Hawkins SJ (2004) Physical 
stress and biological control regulate the producer-consumer balance in intertidal biofilms. Ecology 85: 1372-1382

Tilman D (1996) Biodiversity: population versus ecosystem stability. Ecology 77:350-363

Tilman D (1999) The ecological consequences of changes in biodiversity: a search for general principles. Ecology 80 : 1455-1474

Tilman D, Lehman C (2001) Human-caused environmental change: impacts on plant diversity and evolution. Proc Natl Acad Sci USA 98:5433-5440

Tole L (2002) Habitat loss and anthropogenic disturbance in Jamaica's Hellshire Hills area. Biodivers Conserv 11: 575-598

Ugarte RA, Sharp G (2001) A new approach to seaweed management in eastern Canada: the case of Ascophyllum nodosum. Cah Biol Mar 42:63-70

Underwood AJ (1989) The analysis of stress in natural populations. Biol J Linn Soc 37:51-78

> Valdivia N, Gollety C, Migne A, Davoult D, Molis M (2012) Stressed but stable: canopy loss decreased species synchrony and metabolic variability in an intertidal hardbottom community. PLoS ONE 7:e36541

Vitousek PM, Aber JD, Howarth RW, Likens GE and others (1997a) Human alteration of the global nitrogen cycle: sources and consequences. Ecol Appl 7:737-750

> Vitousek PM, Mooney HA, Lubchenco J, Melillo JM (1997b) Human domination of Earth's ecosystems. Science 277: 494-499

> Walker DI, Kendrick GA (1998) Threats to macroalgal diversity: marine habitat destruction and fragmentation, pollution and introduced species. Bot Mar 41:105-112

> Watson J, Estes JA (2011) Stability, resilience, and phase shifts in rocky subtidal communities along the west coast of Vancouver Island, Canada. Ecol Monogr 81:215-239

Editorial responsibility: Lisandro Benedetti-Cecchi, Pisa, Italy
Watson DC, Norton TA (1987) The habitat and feeding preferences of Littorina obtusata (L.) and L. mariae Sacchi et Rastelli. J Exp Mar Biol Ecol 112:61-72

Watt CA, Scrosati RA (2013) Bioengineer effects on understory species richness, diversity, and composition change along an environmental stress gradient: experimental and mensurative evidence. Estuar Coast Shelf Sci 123: 10-18

Wheeler PA, North WJ (1980) Effect of nitrogen supply on nitrogen content and growth rate of juvenile Macrocystis pyrifera (Phaeophyta) sporophytes. J Phycol 16:577-582

> Worm B, Duffy JE (2003) Biodiversity, productivity and stability in real food webs. Trends Ecol Evol 18:628-632

> Worm B, Lotze HK (2006) Effects of eutrophication, grazing, and algal blooms on rocky shores. Limnol Oceanogr 51: 569-579

> Worm B, Lotze HK, Bostrom C, Engkvist R, Labanauskas V, Sommer U (1999) Marine diversity shift linked to interactions among grazers, nutrients and propagule banks. Mar Ecol Prog Ser 185:309-314

Worm B, Reusch T, Lotze H (2000) In situ nutrient enrichment: methods for marine benthic ecology. Int Rev Hydrobiol 85:359-375

Worm B, Lotze HK, Hillebrand H, Sommer U (2002) Consumer versus resource control of species diversity and ecosystem functioning. Nature 417:848-851

> Worm B, Barbier EB, Beaumont N, Duffy JE and others (2006) Impacts of biodiversity loss on ocean ecosystem services. Science 314:787-790

> Yachi S, Loreau M (1999) Biodiversity and ecosystem productivity in a fluctuating environment: the insurance hypothesis. Proc Natl Acad Sci USA 96:1463-1468

Ylla I, Romani AM, Sabater S (2007) Differential effects of nutrients and light on the primary production of stream algae and mosses. Fundam Appl Limnol 170:1-10

Submitted: April 15, 2014; Accepted: May 15, 2015

Proofs received from author(s): August 7, 2015 